\title{
X-ray tomography of a soil block: a useful tool for the restoration of archaeological finds
}

\author{
Alessandro Re ${ }^{1,2^{*}}$, Jacopo Corsi ${ }^{1,2}$, Marco Demmelbauer ${ }^{3,4}$, Margherita Martini $^{1}$, Giorgia Mila ${ }^{1,2}$ and Chiara Ricci $^{3}$
}

\begin{abstract}
Introduction: X-ray imaging is a very powerful tool which can be exploited in several fields. In the last few years, its use in archaeology has grown consistently. One of the most recent and interesting applications of computed $X$-ray tomography $(C T)$ is the analysis of soil blocks, coming from excavations, in order to seek for finds of different kinds and materials possibly contained therein. For this purpose, both medical and industrial CT scanners have been employed. In this paper, the application of a CT instrument specifically designed and developed for the analysis of Cultural Heritage materials is presented. We analysed a soil block extracted from a necropolis in the Italian region of Abruzzo and probably dating back to the VI-IV century B.C., which was found to contain a bronze belt.

Results: Thanks to the versatility of the CT equipment we designed, a complete scan has been obtained in less than four hours and has delivered extremely useful information in a completely non-invasive way. The CT dataset and images allowed a virtual extraction of the find to be performed before the actual stratigraphic recovery that, in this case, was simplified thanks to the merging of the archaeological evidences and with information coming from scientific analyses. The information provided by the tomography consisted in: the distribution, shape and dimensions of fragments composing the artefact; indications about its general conditions; the recognition of repairs done in the past and the presence of different materials (although not precisely identified).

Conclusions: The use of CT has great potential for the work of both archaeologists and restorers. The indirect extraction of an artefact from an archaeological excavation, which entailed moving a soil block to the laboratory, allowed one to reconstruct almost all its parts and to collect information about materials. $C T$ analysis has been particularly useful for determining both its conditions and its repairs before the actual recovery, thereby facilitating the restoration process. The recovery and conservation of an historical piece like the one presented here can help archaeological and conservation studies, enrich a museum collection and contribute to the dissemination of acquired cultural information.
\end{abstract}

Keywords: Computed tomography (CT), Cultural heritage, Archaeology, Soil block, Restoration

\section{Introduction}

$\mathrm{X}$-ray imaging provided important contributions to archaeology, especially in the recent years, both through radiography [1-4] and tomography [5]. X-ray computed tomography (CT) has been used in many cases because of its potential to visualise inner and invisible parts of an object, providing information in a completely non-invasive way. Thanks to their availability medical CT scanners have often been used in the archaeological field: to investigate mummies and related materials

\footnotetext{
* Correspondence: alessandro.re@unito.it

'Dipartimento di Fisica, Università di Torino, via Pietro Giuria 1, 10125 Torino, Italy ${ }^{2}$ Istituto Nazionale di Fisica Nucleare, Sezione di Torino, via Pietro Giuria 1, 10125 Torino, Italy

Full list of author information is available at the end of the article
}

[6-8], to discover the content of a pot before opening it $[9,10]$ or simply to study the inner and outer of an object in high detail [11]. CT proved to be a very powerful tool even in the related field of anthropology $[12,13]$. Synchrotron radiation can also be used for some special cases [14]; an example was presented of a dedicated transportable instrument developed specifically to analyse fossils [15].

The analysis of soil blocks from excavations is one of the most recent applications of $\mathrm{CT}$ in the field of archaeology. Medical [16] and industrial $[17,18]$ scanners have been employed so far to scan the blocks in the search for artefacts of different nature. In this paper we would like to present the application of a CT instrument 
[19] specifically designed for the analysis of Cultural Heritage materials. This instrument has been developed within the neu_ART project [20] and installed in the Centre for Conservation and Restoration "La Venaria Reale": although it has already demonstrated its reliability and usefulness for the analysis of large artworks [21], however, thanks to its versatility both in energies and geometry, it proved suitable for the analysis of artefacts from an archaeological excavation too.

\section{The archaeological recovery and restoration}

The soil block we analysed was extracted in the necropolis of Villalfonsina, discovered in the province of Chieti (Abruzzo, Italy) and probably dating back to the VI-IV century B.C. [22]. It is one among several other blocks excavated in the same and surrounding areas and containing artefacts of very different use (weapons, finely decorated objects, clothing accessories). This block contained a decorative, elegant and wide bronze belt for men, worn by the deceased. It is composed of two engraved buckles and a continuous metal belt strap, perforated on both upper and lower edges to fasten a leather strip.

If generally small and well preserved objects are directly recovered during an archaeological excavation, this time an indirect extraction has been carried out: as the find, part of the grave-good, was quite complex and fragile, a large soil block with dimensions $40 \times 15 \times 10 \mathrm{~cm}^{3}$ has been removed (Figure 1). This method of extraction allows safe transport and therefore the micro-excavation can take place in a controlled environment: this helps to preserve even small fragments of the object, delicate materials such as textiles remains and, possibly, to record traces of food offerings produced during the burial (e.g. seeds and pollens). Due to the complexity and fragmentation of the contents of the block, already visible in a preliminary radiograph (Figure 2), a full CT scan has been planned. For this measurement the soil block has been firstly enveloped in a plastic film with low radiopacity and then kept in a vertical position by means of a custom-made plaster support. Thanks to the availability of the dedicated CT equipment at the Conservation and Restoration Centre, the scan has been performed by scientists together with conservators: thus, results have been promptly discussed and the micro excavation and the restoration of the bronze belt have been speeded up and simplified. The CT data helped the recovery of the object, a difficult task because of both the metal composition and the burying manner: in fact the artefact, placed around the body of the deceased, was exposed both to the chemical effects of organic decomposition, that in an anaerobic underground environment produces acids and substances dangerous for the conservation of bronze [23,24], and to the pressure of the burial soil. As these stresses affected the curvature of the belt until it became flat; the heavy corrosion resulted in flaking and splintering of the metal into small fragments. The restoration process allowed to recreate better conservation conditions by arresting or delaying the existing degradation processes and improving the aesthetics of the artefact. Specifically, we proceeded with a stratigraphic excavation that led to the recovery of all the pieces and archaeological relevant information. The artefact has been cleaned by using a micro-drill in order to eliminate the soil concretions and dangerous corrosion products; finally, the object was reconstructed using pigmented epoxy resin and has been protected with acrylic resins and microcrystalline waxes.

\section{Experimental setup}

The tomographic system used for this measurement is described in detail in Ref. [19]: it is composed of an Xray tube, a rotating platform and a linear X-ray detector which scans the projection plane thanks to a high precision mechanical system. The equipment is installed in a shielded area and it operates remotely through a fully automated acquisition procedure. For this measurement 540 projections have been acquired: each one has been obtained by means of a horizontal translation of the

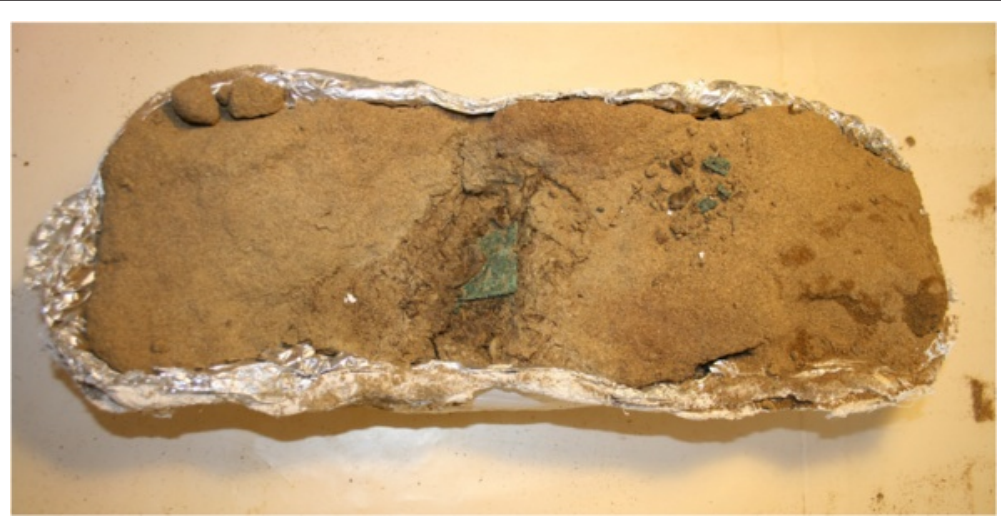

Figure 1 The soil block. The appearance of the soil block as arrived at the restoration laboratory after its extraction in the archaeological excavation. 


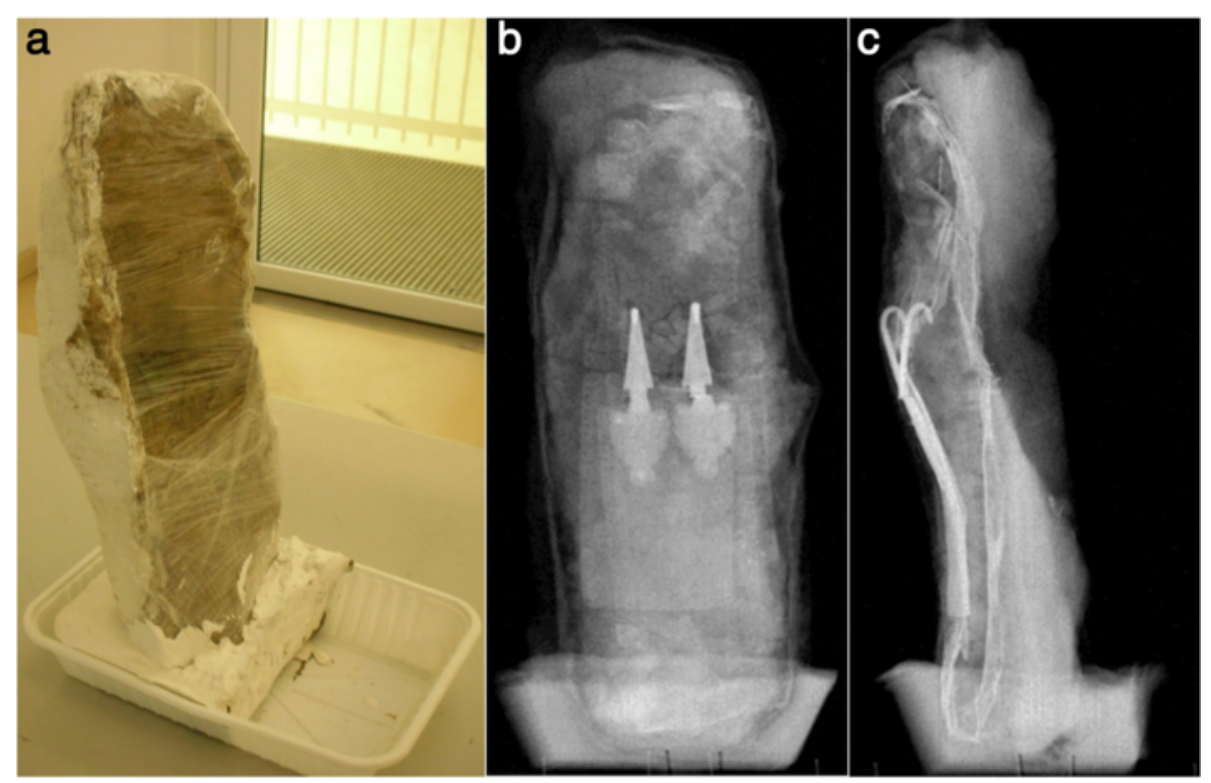

Figure 2 Radiographs. A picture (a) and two radiographs (b-c) of the soil block viewed from different angles.

detector of $26 \mathrm{~cm}$ (at a speed of $2 \mathrm{~m} / \mathrm{min}$ ) and a following rotation of the object (up to a final rotation of $270^{\circ}$, with one image acquired each $0.5^{\circ}$ ). The X-ray source has been used at its maximum tube voltage and power, $200 \mathrm{kV}$ and $900 \mathrm{~W}$ respectively, and, to limit the beamhardening effects [25], a $2 \mathrm{~mm}$ thick aluminium slab has been introduced to absorb the softer X-rays. The air-cooled tube has been used with cycles of 40 minutes of irradiation and 20 minutes of cooling to avoid overheating.

A summary of the parameters of the experimental setup is shown in Table 1.

To minimize the penumbra effect due to the focal spot size, the object-detector distance was chosen as the minimum achievable, while the source-detector distance was set large enough to obtain good resolution while keeping a reasonable signal intensity.

A non-rotating marker was added in the image field, allowing to check and refine the horizontal alignment of all the projections. Moreover, several open beam and dark projections have been acquired for later use in the image-processing stage. In Figure 2 two radiographs acquired at different angles are shown (already corrected using the open beam and the dark images). The CT reconstruction was performed with a non-commercial software-utility developed by Dan Schneberk of the Lawrence Livermore National Laboratory (USA), using the approximation of fan beam geometry and the filtered back-projection algorithm [25]. The commercial software VGStudio MAX 2.2 of Volume Graphics was used both to visualise the $3 \mathrm{D}$ rendering and to perform the segmentation of the data. Some examples of threedimensional rendering are shown in Figure 3.

\section{Results and discussion}

As already discussed, a preliminary radiograph obtained with the same CT equipment indicated the complexity of the recovery, but only the CT rendering delivered a detailed overview of the content of the soil block. In fact it shows the exact position of the various elements and their fragmentation, as well as the stratification of materials. The CT dataset and images allowed a virtual recovery of the find to be performed before the actual stratigraphic

Table 1 Experimental setup

\begin{tabular}{ll}
\hline Soil block dimensions & $40 \times 15 \times 10 \mathrm{~cm}^{3}$ \\
Source-Detector Distance (SDD) & $2.94 \mathrm{~m}$ \\
Source-Object Distance (SOD) & $2.64 \mathrm{~m}$ \\
Object-Detector Distance (ODD) & $0.30 \mathrm{~m}$ \\
Magnification & $\times 1.11$ \\
Detector pixel size & $200 \mu \mathrm{m}$ \\
Reconstructed voxel size & $180 \mu \mathrm{m}$ \\
Tube voltage & $200 \mathrm{kV}$ \\
Current & $4.5 \mathrm{~mA}$ \\
Focal spot size & $3 \mathrm{~mm}$ \\
Detector scan speed & $2 \mathrm{~m} / \mathrm{min}$ \\
Number of projections & 540 \\
Angular step & $0.5^{\circ}$ \\
Scanned area & $26 \times 51.2 \mathrm{~cm}^{2}$ \\
Image dimensions & $1300 \times 2560 \mathrm{pixel}^{2}$ \\
Output & $12 \mathrm{bit}$ \\
Acquisition time & $3 \mathrm{~h} 40 \mathrm{~min}$ \\
\hline Detils of the experimentalsetup &
\end{tabular}

Details of the experimental setup. 


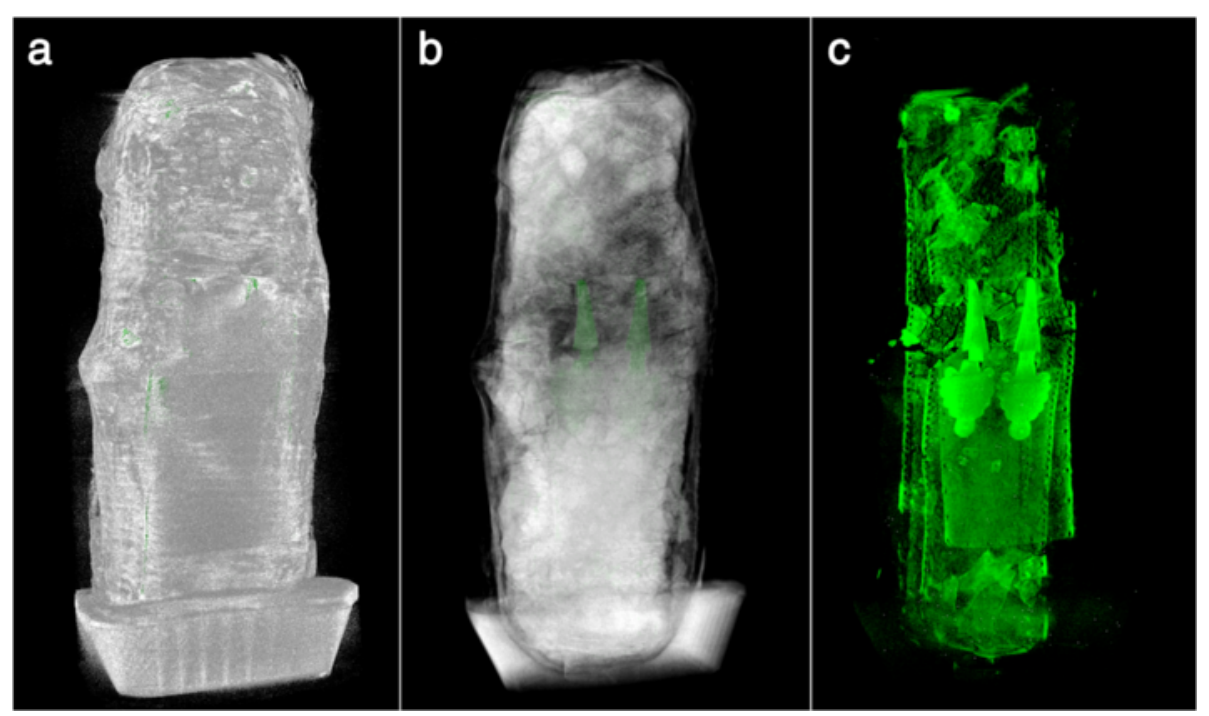

Figure 3 CT 3D rendering. 3D rendering of the $C T$ volume of the soil block: (a) complete volume; (b) transparency effect of the earth; (c) segmentation of the metallic parts inside the soil block.

recovery. Below some of the main results obtained by the CT are listed, highlighting how they have been used by the restorers for the extraction and final display of the find.

In Figure 3 a segmentation of the 3D rendering has been shown, highlighting the metal elements inside the soil block: the distortion of the curved portions of the belt is evident and they are almost entirely destroyed and lost. Thanks to this information, it was possible to place each small fragment in its original position. CT is very useful for this purpose, and sometimes provide also information about the mineralization condition of metal: in this particular case, the thickness of the foil was so thin

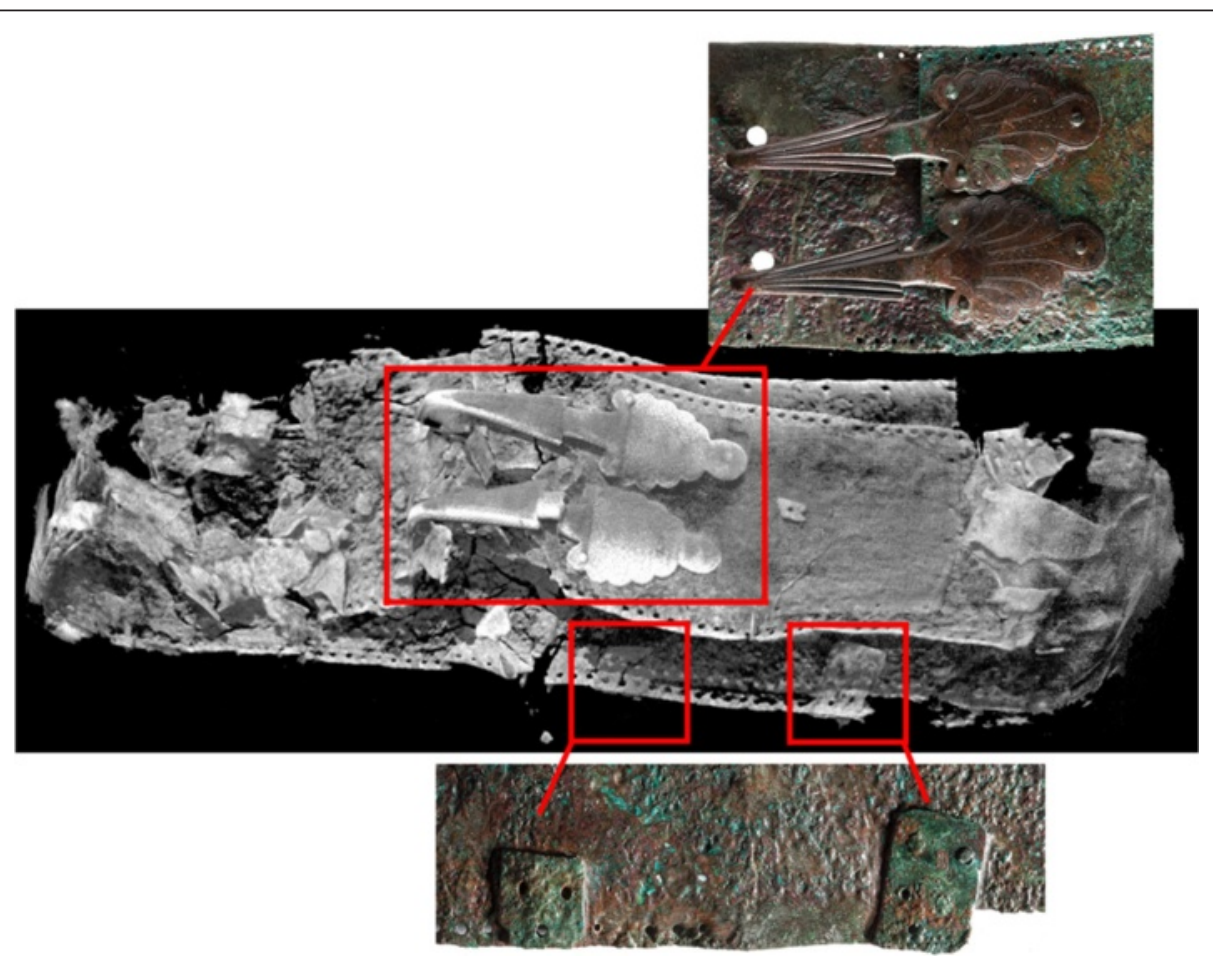

Figure $4 \mathrm{CT}$ overview. 3D rendering of the segmentated $\mathrm{CT}$ volume highlighting the metal parts inside the soil block. In colours two pictures of the belt after the restoration are shown: the details of the buckles and of two repairs. 


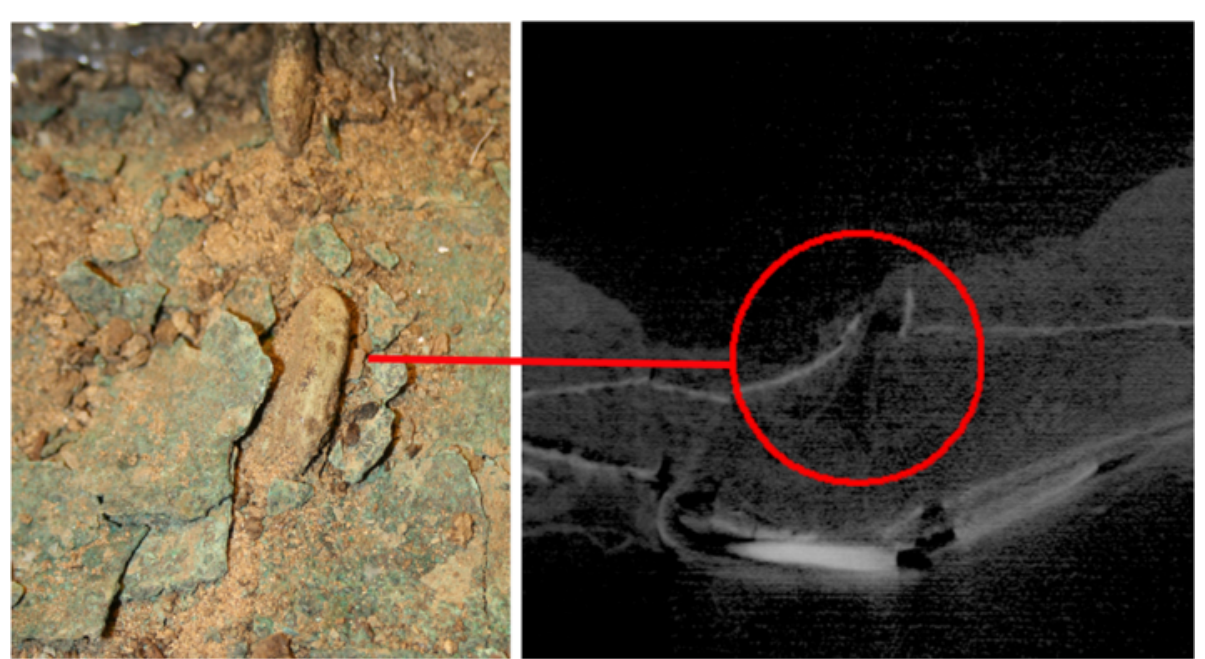

Figure $\mathbf{5}$ CT horizontal section. Picture of a detail during the micro-excavation and CT horizontal section showing a vertebra bone breaking the metal belt.

that it was not possible to clearly observe the differences between mineralized and metallic zones. Using the same segmentation, in Figure 4 both buckles are clearly visible, showing a distinctive decoration, as well as two thicker areas of the metal foil, difficult to be interpreted by CT images alone. During the restoration process, they were found to be repairs of the belt made in antiquity and obtained with replacement bronze slabs fastened with rivets of the same material. These repairs were executed to extend the lifetime of the object regardless of its aesthetics.

Furthermore the CT reconstruction allowed to detect other materials, even if less clearly than metals: for example, in Figure 5, a CT horizontal section shows one of the deceased's vertebrae (later found during the microexcavation) that broke the metal belt and contributed to the distortion and the fragmentation of the belt itself. Moreover, CT images suggests the presence of two additional porous and cracked layers around the artefact, unidentifiable but clearly different from the homogeneous and compact layer made by sand-like burial soil (Figure 6). During the micro-excavation it was established that one of them is a large piece of leather, completely degraded and disintegrated, and another one is an organic layer, related to the base level of the grave. Both organic layers were taken using gauze fixed with acrylic resin. It is worth to note that the leather layer has been recovered

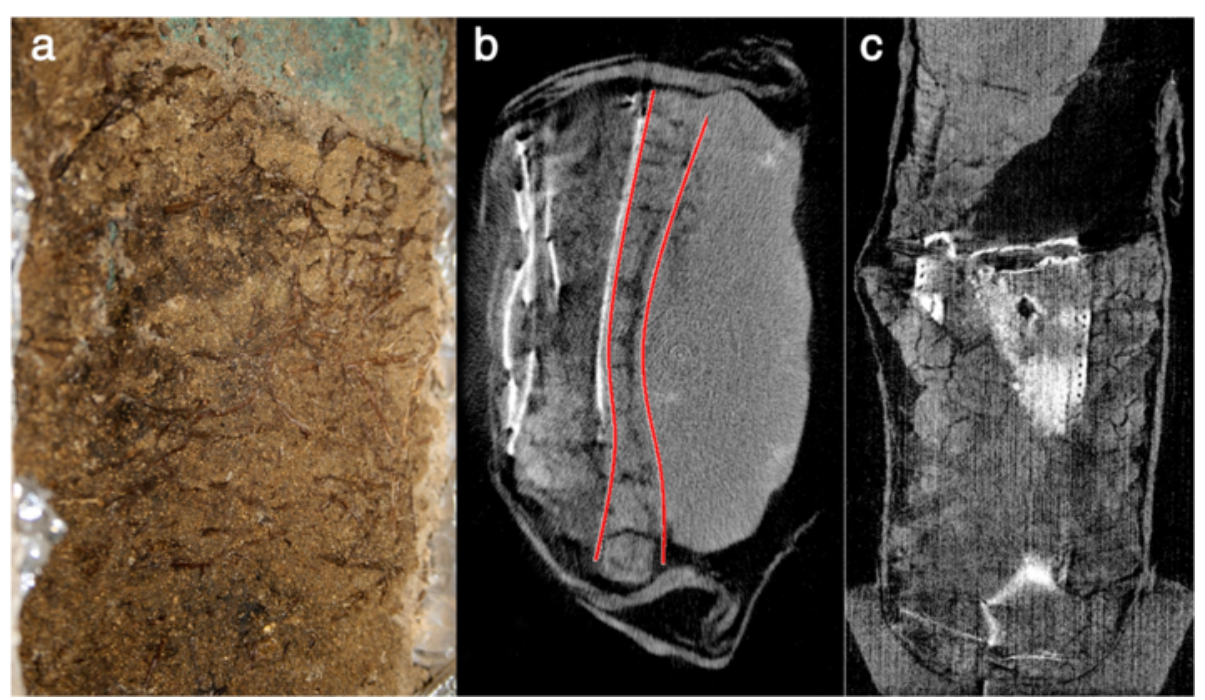

Figure 6 CT horizontal and lateral sections. (a) picture of a detail during the micro-excavation; CT horizontal (b) and lateral (c) sections showing porous and cracked layers around the artefact. 


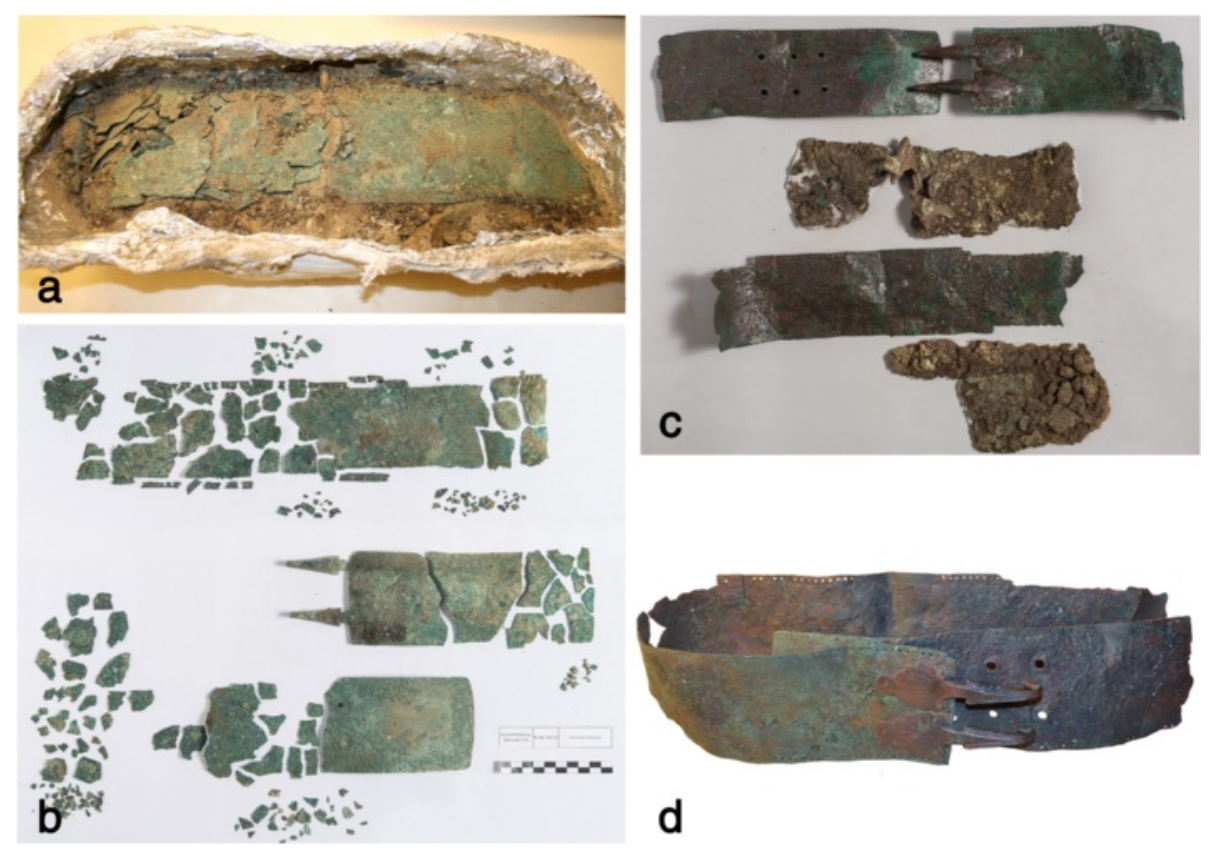

Figure 7 Different phases of the restoration of the belt. Picture of the different phases of the restoration: (a) during the micro-excavation; (b) just after the micro-excavation; (c) at the end of the restoration with organic layers; (d) final appearance of the artefact.

thanks to the information provided by the CT scan. The result of the restoration process, together with some intermediate phases, is shown in Figure 7.

\section{Conclusions}

This paper has confirmed the high potential of tomography for both archaeologists and restorers. The removal of a soil block from the archaeological excavation and the indirect extraction of the artefact performed later in a controlled environment allowed to recover information about the material contained therein and to replace correctly almost all the fragments. The use of CT for the analysis of this artefact has been particularly useful for determining its conservation conditions before the actual recovery, thereby facilitating the restoration process. The presence of a custom-made instrument in a Centre for Conservation and Restoration avoids risky transports of delicate materials to other labs to perform CT scan.

The information provided by the tomography consisted in: the distribution, shape and dimensions of the fragments composing the artefact; indications about the state of conservation; the presence of repairs done in the past and the presence of different materials (although not precisely identified).

The recovery and conservation of an historical object like the one presented here can help archaeological and conservation studies, enrich a museum collection and contribute to the dissemination of acquired cultural information.

\section{Competing interests}

The authors declare that they have no competing interests.

\section{Authors' contributions}

JC performed the data acquisition. AR, MM, CR performed the data analysis. $A R, M D, M M, G M, C R$ interpreted $X$-ray imaging. MD studied the artefact and directed the restoration. AR and MD wrote the manuscript and all authors revised it critically. All authors read and approved the final manuscript.

\section{Acknowledgements}

This study was carried out in the framework of the neu_ART research project funded by Regione Piemonte. All the neu_ART collaboration is warmly acknowledged for the development of the CT instrument and for the support to this work. We express our gratitude to the Superintendence for Archaeological Heritage of Abruzzo, particularly to Dr. Annamaria Faustoferri and Dr. Isabella Pierigé. We also thank the student Chiara Armigliato, who performed an exemplary restoration of the belt during the course of the Conservation and Restoration of Cultural Heritage at the University of Turin, and Dr. Stefano Argirò, for his help in the English revision of this paper.

\section{Author details}

${ }^{1}$ Dipartimento di Fisica, Università di Torino, via Pietro Giuria 1, 10125 Torino, Italy. ${ }^{2}$ Istituto Nazionale di Fisica Nucleare, Sezione di Torino, via Pietro Giuria 1, 10125 Torino, Italy. ${ }^{3}$ Centro Conservazione e Restauro "La Venaria Reale", Piazza della Repubblica, 10078 Venaria Reale, Torino, Italy. ${ }^{4}$ SUSCOR, Università di Torino, Piazza della Repubblica, 10078 Venaria Reale, Torino, Italy.

Received: 9 June 2014 Accepted: 9 January 2015

Published online: 03 February 2015

\section{References}

1. Wevers M, de Meester P, Lodewijckx M, Ni Y, Marchal G, Jiang Y, et al. Applications of microfocus $X$-ray radiography in materials and medical research. NDT E Int. 1993;26(3):135-40.

2. Corfield M. Radiography in archaeology. Phys Educ. 1995;30(6):360.

3. Deschler-Erb E, Lehmann EH, Pernet L, Vontobel P, Hartmann S. The complementary use of neutrons and $\mathrm{X}$-rays for the non-destructive 
investigation of archaeological objects from Swiss collections. Archaeometry. 2004;46(4):647-61.

4. Berg I. Looking through pots: recent advances in ceramics X-radiography. J Archaeol Sci. 2008;35(5):1177-88.

5. van Kaick $G$, Delorme S. Computed tomography in various fields outside medicine. Eur Radiol Suppl. 2005;15(4):D74-81.

6. Jansen RJ, Poulus M, Venema H, Stoker J. Scenes from the past - highresolution spiral CT of Egyptian scarabs. Radiographics. 2002;22:63-6.

7. Chhem RK, Brothwell DR. Paleoradiology. Imaging Mummies and Fossils. Berlin Heidelberg New York: Springer; 2008.

8. Gostner P, Bonelli M, Pernter P, Graefen A, Zink A. New radiological approach for analysis and identification of foreign objects in ancient and historic mummies. J Archaeol Sci. 2013;40:1003-11.

9. Anderson T, Fell C. Analysis of roman cremation vessels by computerized tomography. J Archaeol Sci. 1995;22:609-17.

10. Minozzi S, Giuffra V, Bagnoli J, Paribeni E, Giustini D, Caramella D, et al. An investigation of Etruscan cremations by Computed Tomography (CT). Antiquity. 2010;84:195-201.

11. Jansen RJ, Koens HFW, Neeft CW, Stoker J. Scenes from the Past - CT in the Archaeologic Study of Ancient Greek Ceramics. RadioGraphics. 2001;21(2):315-21.

12. Mednikova MB, Dobrovolskaya MV, Viola B, Lavrenyuk AV, Kazansky PR, Shklover VY, et al. A micro computerized tomography (X-ray Microscopy) of the Hand Phalanx of the Denisova girl. Archaeol Ethnol Anthropol Eurasia. 2013:41(3):120-5.

13. du Plessis A, Steyn J, Roberts DE, Botha LR, Berger LR. A proof of concept demonstration of the automated laser removal of rock from a fossil using 3D X-ray tomography data. J Archaeol Sci. 2013;40(12):4607-11.

14. Bernardini F, Tuniz C, Coppa A, Mancini L, Dreossi D, Eichert D, et al. Beeswax as Dental Filling on a Neolithic Human Tooth. PLoS ONE. 2012;7(9):e44904,1-9.

15. Tuniz C, Bernardini F, Cicuttin A, Crespo ML, Dreossi D, Gianoncelli A, et al. The ICTP-Elettra X-ray laboratory for cultural heritage and archaeology. Nucl Instrum Methods Phys Res Sect A. 2013;711:106-10.

16. Jansen RJ, Poulus M, Kottman J, de Groot T, Huisman DJ, Stoker J. CT: A new nondestructive method for visualizing and characterizing ancient roman glass fragments in situ in blocks of soil. Radiographics. 2006;26:1837-44.

17. Stelzner J, Ebinger-Rist N, Peek C, Schillinger B. The application of 3D computed tomography with $\mathrm{X}$-rays and neutrons to visualize archaeological objects in blocks of soil. Stud Conserv. 2010;55(2):95-106.

18. Ebinger-Rist N, Peek C, Stelzner J, Gauß F. Computed Tomography: a Powerful Tool for Non-Destructive Mass Documentation of Archaeological Metals. Metal 2010 :Proceedings of the Interim Meeting of the ICOM-CC Metal Working Group (11-15 October 2010, Charleston, South Carolina, USA) 2011:458-465

19. Re A, Brancaccio R, Corsi J, Cotto G, Dughera G, Ferrarese W, Grassi N, Lo Giudice A, Lusso S, Mereu P, Mila G, Nervo M, Pastrone N, Ricci C, Sacchi R, Visca L, Zamprotta L. The radio-tomographic apparatus. In: II Progetto neu_ART. Studi e applicazioni / Neutron and X-ray tomography and imaging for cultural heritage, Cronache 4. Edited by Editris, Torino, 2013

20. Re A, Albertin F, Bortolin C, Brancaccio R, Buscaglia P, Corsi J, et al. Results of the Italian neu_ART project. IOP Mater Sci Eng (MSE) Conf Proc Ser. 2012;37:012007.

21. Re A, Albertin F, Avataneo C, Brancaccio R, Corsi J, Cotto G, et al. X-ray tomography of large wooden artworks: the case study of "Doppio corpo" by Pietro Piffetti. Herit Sci. 2014;2:19.

22. Demmelbauer M, Martini M, Ricci C: Virtual extraction of "soil clod" from archaeological sites: the tomographic analysis for the restoration of multi-material artifacts. In: II Progetto neu_ART. Studi e applicazioni/Neutron and $\mathrm{X}$-ray tomography and imaging for cultural heritage, Cronache 4. Edited by Editris, Torino, 2013, 115-120

23. J.M. Cronyn. The elements of archaeological conservation. Edited by Routledge, London, 1990, 14-42

24. D. Scott. Copper and bronze in art. Edited by The Getty Conservation Institute, Los Angeles, 2002, 39

25. Kak AC, Slaney M. Principles of computerized tomographic imaging. Edited by: IEEE Press, Piscataway, NJ, 1988

\section{Publish with ChemistryCentral and every scientist can read your work free of charge \\ "Open access provides opportunities to our colleagues in other parts of the globe, by allowing anyone to view the content free of charge." \\ W. Jeffery Hurst, The Hershey Company. \\ - available free of charge to the entire scientific community \\ - peer reviewed and published immediately upon acceptance \\ - cited in PubMed and archived on PubMed Central \\ - yours - you keep the copyright \\ Submit your manuscript here: \\ http://www.chemistrycentral.com/manuscript/ \\ () \\ Chemistry Central}

